\title{
A neo-Pyrrhonian response to the disagreeing about disagreement argument
}

\author{
Diego E. Machuca1
}

Received: 10 October 2015 / Accepted: 30 December 2015 / Published online: 2 February 2016

(C) Springer Science+Business Media Dordrecht 2016

\begin{abstract}
An objection that has been raised to the conciliatory stance on the epistemic significance of peer disagreement known as the Equal Weight View is that it is selfdefeating, self-undermining, or self-refuting. The proponent of that view claims that equal weight should be given to all the parties to a peer dispute. Hence, if one of his epistemic peers defends the opposite view, he is required to give equal weight to the two rival views, thereby undermining his confidence in the correctness of the Equal Weight View. It seems that the same objection could be leveled against those who claim to suspend judgment in the face of pervasive unresolvable disagreements, as do the Pyrrhonian skeptics. In this paper, I explore the kind of response to the objection that could be offered from a neo-Pyrrhonian perspective, with the aim of better understanding the intriguing character of Pyrrhonian skepticism.
\end{abstract}

Keywords Pyrrhonian skepticism - Suspension of judgment - Disagreement . Conciliationism $\cdot$ Equal weight view $\cdot$ Self-defeat $\cdot$ Self-refutation $\cdot$ Rationality

\section{Introduction}

There is at present a heated and fertile debate about which doxastic attitude one is rationally required to adopt when involved in a disagreement with someone whom one regards as an epistemic peer. Two subjects are deemed to be epistemic peers with respect to a given topic when they share roughly the same evidence bearing on that topic, possess similar cognitive virtues or skills, and make use of these virtues or skills in the evaluation of the evidence. Two main positions have been defended

\footnotetext{
$凶 \quad$ Diego E. Machuca

diegomachuca@conicet.gov.ar

1 Consejo Nacional de Investigaciones Científicas y Técnicas, Buenos Aires, Argentina
} 
in the literature on the epistemic significance of peer disagreement: conciliationism and steadfastness. Roughly put, whereas conciliationists claim that all the parties to a peer dispute should significantly revise their beliefs, proponents of steadfast views maintain that, in at least a considerable number of cases, upon learning about a peer's disagreement one can retain one's belief with a degree of confidence that is either identical or close to one's initial degree of confidence.

A prominent version of conciliationism is the Equal Weight View, which can be formulated thus:

\section{Equal Weight View (EWV)}

It is rationally required to give equal weight to the opinions of all the parties to a peer dispute when there is no undefeated reason for preferring one opinion to the others that is independent of the very disagreement between the disputants.

A serious charge that has been leveled particularly against EWV is that it is selfdefeating, self-undermining, or self-refuting. The reason is that its proponent is forced to give equal weight both to it and to the opposite view in the event that one of his epistemic peers disagrees with him about the correctness of EWV, with the result that his confidence in this view will be undermined. I call this charge 'the disagreeing about disagreement argument' (DDA).

Unbeknownst to most participants in the current debates on disagreement in epistemology, metaethics, and philosophy of religion, the epistemic and practical problems posed by the existence of long-standing and widespread controversies were a major topic of discussion in ancient Pyrrhonism. Anyone familiar with the extant writings of Sextus Empiricus knows that disagreement in one or another form plays a crucial role in the Pyrrhonian argumentative strategies devised to induce across-the-board suspension of judgment. The reason for this reference to Pyrrhonism is that it seems that DDA could also be leveled against this form of skepticism in an attempt to show that across-the-board suspension of judgment is self-defeating or self-refuting. In this paper, I would like to explore the kind of response that a present-day Pyrrhonist (a 'neo-Pyrrhonist') could offer to that argument because I think this might help us to better appreciate the intriguing character of Pyrrhonian skepticism.

In Sect. 2, I will examine the Agrippan mode from disagreement and the relation between suspension and equipollence - namely, whether the Pyrrhonist takes suspension to be the attitude he is rationally required to adopt when faced with disputes between views that strike him as epistemically equipollent. In so doing, I will refer to his ad hominem style of argumentation and to his stance on the norms of rationality. This will provide a rough idea of the Pyrrhonist's sui generis outlook. In Sect. 3, I will present DDA in more detail, examining to which kind of self-defeat it refers and whether it should be considered a type of self-refutation argument. In Sect. 4, I will review some responses that have been proposed in defense of EWV and conciliationism in general, and explain why none of them is the kind of response a neo-Pyrrhonist would offer. In Sect. 5, by appealing to what I take to be the Pyrrhonist's stance on the connection between suspension and equipollent disagreement, I will propose a neo-Pyrrhonian response to DDA, attempting to show that, even though this argument might be efficacious against EWV and conciliationism more generally, it does not represent a problem for Pyrrhonian skepticism. In Sect. 6, I will consider a number 
of objections that could be raised to the neo-Pyrrhonian response to DDA and explain why they miss the mark.

\section{Disagreement and Pyrrhonian suspension}

Contemporary discussions of the so-called Pyrrhonian problematic tend to overlook the dialectical aspect of Sextus Empiricus's presentation of Pyrrhonism. ${ }^{1}$ For they do not take into account the justificatory challenge posed by the existence of disagreements, but focus on three of the Five Modes of Agrippa, namely, infinite regress, reciprocity, and hypothesis - the famous Agrippa's trilemma. This set of modes, however, also includes the modes of disagreement and relativity. Sextus explains the former thus:

The mode from disagreement is that by means of which we discover that, with regard to the matter proposed, there has arisen, both in ordinary life and among philosophers, an undecidable dispute owing to which we end up in suspension of judgment, since we are not able to choose or to reject anything. (Pyrrhonian Outlines [hereafter $P H]$ I 165$)^{2}$

It is not of course the mere existence of a disagreement about a given matter that leads us to suspend judgment about that matter, but the existence of a disagreement that we cannot resolve. A Pyrrhonist characterizes a dispute as undecidable or unresolvable not in the sense that it is not in itself susceptible of resolution, but in the sense that up to now ${ }^{3}$ he has in fact been unable to pick one of the rival views because they strike him as equipollent or equally credible. As could not be otherwise, interpreters do not agree about the nature of the connection between equipollence and suspension: while some view it as a requirement of rationality, others think that it is a merely psychological constraint. ${ }^{4}$ These two ways of interpreting the connection in question concern the Pyrrhonist's general stance on rationality and, as we will see in Sects. 5 and 6, have implications as to the possibility of a successful neo-Pyrrhonian response to DDA.

According to the first interpretation, the Pyrrhonist is committed to certain canons or principles of rationality such as the following:

\section{Rational Suspension}

It is rationally required to suspend judgment in the face of a disagreement that one is unable to resolve due to the apparent epistemic equipollence of the conflicting views.

\footnotetext{
1 An exception is Lammenranta (2008, 2011). Cf. Machuca (2015).

2 All translations of Sextus's texts are mine.

3 In line with his open-minded and cautious attitude, Sextus constantly employs temporal phrases such as "so far," "up till now," or "up to the present" to make it clear that the Pyrrhonist restricts himself to reporting on what has hitherto happened to him.

4 For the view that suspending judgment in the face of equipollent disagreement is a requirement of rationality, see Pentzopoulou-Valalas (1994) and Perin (2006, pp. 358-359 with n. 32; 2010, Chap. 2). For the contrary view, see e.g. McPherran (1987, pp. 318-320), Barnes (1990, pp. 2610-2611), and Machuca (2011, pp. 71-72; 2013b, Sect. 4).
} 
This may seem to be the natural reading of the Sextan texts. It is in fact endorsed not only by a number of scholars of ancient Pyrrhonism but also by some contemporary epistemologists with a certain familiarity with those texts. For instance, when briefly referring to Sextus's mode from disagreement, Thomas Kelly affirms that the Pyrrhonian modes are "designed to rationally induce suspension of judgment" (2005, p. 169), and he seems to think that the Pyrrhonist himself takes suspension to be rationally grounded. This interpretation is reasonable because, when a person believes, disbelieves, or withholds judgment on a given proposition, he is taken to be normatively committed to regarding the attitude he adopts as rationally appropriate (e.g., Turri 2012, p. 361).

In line with the interpretation under consideration, the use of arguments such as Agrippa's Five Modes might be taken to indicate that the Pyrrhonist adheres to certain norms or criteria of justification and reasoning, and the use of arguments in general might be taken to show that he accepts the rules of inference. In addition, his suspension of judgment seems to entail a doxastic commitment to the truth of the principle of noncontradiction, since his reason for suspending judgment about which of the parties to a dispute, if any, is correct is that their conflicting views strike him as epistemically equipollent and they cannot all be right. It may therefore be taken as plain that the Pyrrhonist accepts in propria persona certain logical principles, inference rules, and criteria of justification and reasoning.

According to the second interpretation of the connection between equipollence and suspension, which I favor, the latter is not an attitude the Pyrrhonist believes he is rationally required to adopt when unable to settle a given controversy, but a state of mind in which he in fact finds himself after the consideration of rival arguments that strike him as having the same credibility. Suspension should be understood as a psychological disposition that is forced upon him. Note in this regard that Sextus explains that the skeptical way is called " "suspensive' because of the affection ( $\pi \alpha \dot{\alpha} \theta$ os) that comes about in the inquirer after the investigation" ( $P H$ I 7). A $\pi \alpha \dot{\alpha} \theta$ o is that which happens to someone or something as a result of being affected by an agent in the broad sense of this term. It refers to the physical and/or psychological state or condition in which the affected person or thing is. In the present case, this means that suspension is the psychological effect of being confronted with conflicting claims or arguments that appear equally credible to one. To the extent that it is a $\pi \alpha \theta_{0}$ s suspension is something that the Pyrrhonist accepts involuntarily, in much the same way in which he accepts $\pi \alpha \dot{\theta} \theta \eta$ such as hunger and thirst, coldness and heat $(P H \mathrm{I} 13,19)$. We might thus regard suspension as a state of mind that supervenes on the Pyrrhonist as a result of his own psychological constitution. It is by virtue of this constitution that he cannot refrain from withholding his assent whenever conflicting views strike him as epistemically equipollent. This interpretation gains further support from two other texts. When explaining the skeptical expression, "I suspend judgment," Sextus points out that it makes it clear that "objects appear to us equal in respect of credibility and lack of credibility. Whether they are equal, we do not affirm: we say what appears to us about them, when they strike us" (PH I 196). Similarly, in the case of the expression "non-assertion," which is another way of referring to suspension of judgment, Sextus remarks that "it is clear that we do not use 'non-assertion' to mean that objects are in their nature such as to move us necessarily to non-assertion, but rather to make it clear 
that now, when we utter it, we are affected in this way with regard to the matters under investigation" (PH I 193). Besides remarking that the Pyrrhonist does not claim that his suspension is grounded on the way things are by nature, in these passages Sextus makes it clear that suspension is a psychological state brought about in the Pyrrhonist after his being confronted with rival views that strike him as equally credible. For the Pyrrhonist merely reports on the way he is affected and says that things appear equal to him. It is important to note that the Pyrrhonist's suspension of judgment is global, since he says to suspend judgment about all matters of inquiry-more precisely, all the matters of inquiry he has so far considered (see e.g. PH I 31, 205; Adversus Dogmaticos V 144). ${ }^{5}$ The Pyrrhonist would describe his stance thus:

\section{Psychological Suspension}

Up to now, I have found myself psychologically constrained to suspend judgment in the face of a disagreement when the conflicting views have appeared to me to be epistemically equipollent.

According to the interpretation I am defending here, there is in general no doxastic commitment to the canons of rationality on the Pyrrhonist's part. This does not mean that his thinking does not proceed in accordance with certain logical principles, inference rules, and standards of justification and reasoning. Before becoming a full-blown skeptic, he was a Dogmatist ${ }^{6}$ with a full range of beliefs and commitments that were the product of his upbringing, education, professional training, and interpersonal relationships in a given social, cultural, and philosophical context. One may suppose that such factors continue to exert a significant influence on him. Moreover, his state of suspension is induced by the consideration of arguments that appear to be equipollent to him. That is, the Pyrrhonist ends up suspending judgment as a result of a certain use of reason, and in this sense it could be argued that he is rationally required to suspend judgment. After all, the way things appear to him is shaped by different factors, one of which is his natural capability of thinking ( $P H$ I 24). None of this implies, however, that he regards rational principles, rules, and criteria as correct and immune to doubt. In other words, this does not imply that he believes that reason has epistemic value, that is, that reason is in general a reliable way to attain truth and avoid error concerning the questions we investigate. We should bear in mind that neither the fact of our being equipped with certain faculties nor the fact of our thinking in accordance with certain logical principles, inference rules, and criteria of reasoning entail that such faculties, principles, rules, and criteria grant us access to reality, the nature of things, or the truth. The Pyrrhonist makes an extensive use of reason, but it is not a normative use. I have elsewhere suggested that the right way to describe his stance is not as a form of

\footnotetext{
5 Among specialists in Sextan Pyrrhonism, there is a long-running debate about the scope of suspension of judgment, some claiming that it applies across the board, others that it is restricted to theoretical beliefs, leaving untouched ordinary or commonsense beliefs. Engaging in this debate is beyond the purpose of this paper. For a bibliographical overview of the topic, see the relevant sections in Machuca (2013c).

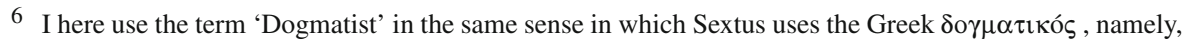
to designate anyone who, on the basis of what he takes to be objective evidence and sound arguments, makes assertions about the nature of things or about non-evident matters.
} 
anti-rationalism, but of a-rationalism, by which I mean that he neither is committed to the canons of rationality nor denies their truth or correctness. ${ }^{7}$

It is also crucial to keep in mind that the Pyrrhonist's argumentative practice against his Dogmatic opponents is at least in part ad hominem, i.e., he attempts to show that their own commitments require them to accept views or to adopt attitudes that they say to reject. Thus, given that his Dogmatic rivals do endorse certain logical principles, standards of justification and reasoning, and inference rules, the Pyrrhonist applies these in his skeptical arguments to show the Dogmatists that, according to their own normative commitments, they are required to suspend judgment. Regarding the effect of those arguments on himself, he would say that, when in his own reflection on any subject of inquiry he applies the rules and criteria used by philosophers and ordinary people, he ends up in a state of aporia or impasse.

Although the interpretation of the Pyrrhonist's general stance on rationality just sketched is probably not accepted by many interpreters, its correctness will be taken for granted in this paper. Even if we came to the conclusion that such an interpretation is mistaken, it would still present an alternative form of Pyrrhonian skepticism whose philosophical implications are, I think, worth considering. This is therefore the skeptical stance that I will have in mind when proposing, in Sect. 5, the neo-Pyrrhonian response to DDA.

\section{The disagreeing about disagreement argument}

As noted in Sect. 1, EWV is the conciliatory stance according to which, in the face of a disagreement between epistemic peers, equal weight should be given to all the rival positions when there is no undefeated reason for preferring one position to the others that is independent of the very disagreement between the disputants. The discovery that an epistemic peer disagrees with one is taken to be higher-order evidence that one may be mistaken in one's assessment of the first-order evidence bearing on the disputed issue. Whereas some conciliationists understand the idea of giving equal weight to all the rival positions in the sense that the disputants should suspend judgment about the matter at hand, others understand it in the sense that the disputants should split the difference in the degrees of confidence in their respective beliefs. This depends on whether one adopts a coarse-grained or a fine-grained approach to doxastic attitudes, that is, on whether one conceives of belief in terms of degrees of credence or according to an all-or-nothing model.

DDA is a serious objection that has been raised to EWV and that, it seems, could also be raised to the across-the-board suspension of judgment adopted by the Pyrrhonist. According to that argument, if the proponent of EWV finds out that an epistemic peer believes EWV to be false, then he should give this belief the same weight as his own belief in the truth of EWV and hence either suspend judgment about its truth or split the difference in the degrees of confidence with which he and his opponent hold

\footnotetext{
7 See Machuca (2011, pp. 74-75). For a fuller discussion of the Pyrrhonist's extensive but non-normative use of reason, see Machuca (2009, pp. 116-123; 2011, sects. 4 and 5; 2013b, Sect. 4; 2015, sect. III; and forthcoming, sect. 5)
} 
their respective beliefs. EWV is therefore self-defeating or self-undermining because in order to propose it as the rationally required reaction to peer disagreement, its proponent must be maximally confident that it is true, in which case he is however required to significantly lower his confidence in its truth since he knows that there are epistemic peers who reject it. ${ }^{8}$ The advocate of EWV is thus rationally bound by EWV itself to lose confidence in EWV. ${ }^{9}$ If it were argued that EWV applies to every peer disagreement except the one about its own correctness, it would be objected that this is an arbitrary move unless one offered a reason why, from the conciliatory viewpoint of EWV itself, conciliation is not epistemically required in the specific case of that peer disagreement, i.e., why the existence of such a disagreement is not a defeater for endorsing EWV. Or if it were argued that EWV was formulated only in relation to first-order peer disputes and hence only applies to them, the question would arise why it cannot be applied also to second-order peer disputes; and if no compelling reason were provided, then the restriction in question would again seem arbitrary.

In a similar way, it could be argued that, when the Pyrrhonist finds out that most people believe that we should not suspend judgment in the face of most first-order disagreements, he should suspend judgment about whether or not he should suspend judgment. Otherwise, his suspension about all the matters into which he has inquired would not really be global, for there would be a disagreement that he is able to resolve and a theoretical view to which he can give his assent. He is thus faced with a dilemma: either he redefines the scope of his suspension by restricting it to most disagreements (in which case he would have to justify the legitimacy of such a restriction) or defeats his own stance by recommending a view about whose truth he is compelled to suspend judgment.

Before proceeding with the examination of some of the replies to DDA that have been offered in the epistemology literature and of the neo-Pyrrhonist's view on them, it should be asked whether DDA is a self-refutation argument, i.e., whether it intends to show that EWV or Pyrrhonism are self-refuting - in one way or another. As Castagnoli (2010, pp. 3-4) points out, we do not find in the contemporary literature an agreedupon definition or account of self-refutation. But one can say roughly that a selfrefutation argument is taken to be an argument that shows that a given item (typically a proposition) is, by way of some form of self-reference or self-application, falsified or unbelievable or unassertable. ${ }^{10}$

My analysis of the kind of self-refutation at issue in DDA relies on a distinction between different types of self-refutation drawn from Mackie (1964), McPherran

\footnotetext{
8 It is worth noting that, by significantly lowering his confidence in the truth of EWV, the proponent of this view is no longer rationally required to give so much weight to the disagreement of those who endorse steadfastness, a view he does not find plausible on the basis of the first-order evidence. His confidence in the truth of EWV would then increase, but this means that he will again be rationally required to pay more attention to the disagreement of those who endorse steadfastness.

9 DDA, first advanced by Plantinga (2000a, pp. 178-179; 2000b, pp. 446-453) against religious pluralism, has recently been developed at length against EWV by van Inwagen (2013). The objection that EWV is self-defeating is also endorsed by Bergmann (2009, p. 348 with n. 21), Enoch (2010, p. 962 n. 19), Sosa (2010, p. 279), and Thune (2010a, p. 371; cf. 2010b, p. 714).

10 That the item in question is unbelievable or unassertable is of course to be understood in the sense that it cannot be consistently or justifiably believed or asserted.
} 
(1987), and Castagnoli (2010). This taxonomy includes absolute, pragmatic, ad hominem, and operational self-refutation. ${ }^{11}$ Absolute self-refutation occurs when the content of a proposition falsifies the proposition: e.g., the propositions "All propositions are false" or "It can be proved that nothing can be proved," if assumed to be true, imply their own falsehood and therefore cannot be true. Pragmatic self-refutation occurs when the actual way in which a proposition is presented falsifies the proposition: e.g., if the proposition "I am not saying anything" is expressed by saying it or the proposition "I am not writing anything" is expressed by writing it, then they are falsified by the very way in which they are presented. Ad hominem self-refutation occurs when the intended way in which a proposition is presented-i.e., the way in which it is intended to be presented by the person who presents it-is inconsistent with the content of the proposition: e.g., if the proposition "No proof exists" is asserted because it is taken by the speaker to be the conclusion of a sound proof, or the proposition "Sensory evidence is unreliable" is asserted because it is taken by the speaker to be the conclusion of an argument one of whose premises depends on the reliability of sensory evidence, then intending to offer such a proof or argument is inconsistent with the content of the proposition. ${ }^{12}$ Even though in these cases the speaker is conceding malgré lui the falsehood of the proposition, there is no actual falsification of the proposition because, despite what the speaker believes, it is not possible to offer such a proof or argument - whereas it is possible, e.g., to write "I am not writing anything."13 Finally, operational self-refutation occurs when what is implied by asserting a proposition contradicts the asserted content: e.g., if one asserts the proposition "No proposition is true," one commits oneself to the truth of this proposition, for an assertion is a commitment to the truth of the asserted proposition. The operationally self-refuting proposition may in some cases be true, but it cannot be asserted. ${ }^{14}$

Now, DDA does not claim that EWV or Pyrrhonism are absolutely self-refuting, for it does not claim that the content of the propositions that express these stances falsify the propositions. Nor does DDA claim that such stances are pragmatically self-refuting, for nothing in the way the propositions that express them are presented falsifies these propositions. DDA does not claim that such stances are self-refuting in an ad hominem way either, for there is nothing in the intended way in which such stances are presented that is inconsistent with the content of the propositions that express them. Finally, DDA does not claim that such stances are operationally selfrefuting, for asserting the propositions that express them does not falsify the content of

\footnotetext{
11 The reason it is important to analyze this taxonomy is that the articles that discuss DDA do not take it into account and do not offer a detailed examination of what kind of self-refutation, if any, is at issue in that argument.

12 This kind of self-refutation argument is ad hominem in the sense that the person who puts it forward makes use of his opponent's own views (cf. the Pyrrhonist's ad hominem argumentative practice described in Sect. 2).

13 These cases of ad hominem self-refutation must be distinguished from those in which one asserts "It can be proved that nothing can be proved" and "There is reliable sensory evidence that no sensory evidence is reliable" both because in these cases the content of the propositions is falsified and because it is falsified by the very same content.

14 The notion of assertion will be crucial when examining, in Sect. 5, the neo-Pyrrhonist's response to DDA.
} 
the propositions. Rather, DDA claims that EWV or Pyrrhonism cannot be justifiably believed or legitimately asserted in the face of a specific situation, namely, when someone calls into question their correctness or would call it into question if asked. There is clearly self-reference or self-application here, for in such a situation EWV or Pyrrhonism would be undermined in virtue of the attitude that they themselves say should be adopted, or is in fact adopted, whenever one finds oneself in a situation of that very kind. Hence, DDA does not affirm that the propositions that express EWV or Pyrrhonism are false, but that in a given dialectical context they should be applied to themselves with the result that they cannot be legitimately believed or asserted. DDA does not concern the truth-value of those propositions, but which doxastic attitude one can or cannot justifiably adopt towards them. Whether the self-reference or selfapplication in question amounts to self-refutation depends on whether one thinks that all self-refutation arguments are intended to show that a given proposition is falsified by some form of self-reference, or else accepts that some self-refutation arguments are intended to show that a given proposition cannot be justifiably believed or legitimately asserted.

It is most interesting to note that DDA resembles what Castagnoli (2010) describes as the characteristic of the ancient charge of $\pi \varepsilon \rho \tau \tau \rho) \pi \eta$ ("turning round," "overturning," "reversal"), a term usually translated as "self-refutation" because the notion it expresses is the closest to our notion of self-refutation. According to Castagnoli, in ancient Western philosophy self-refutation was not regarded as a logical property of certain propositions considered in isolation, and $\pi \varepsilon \rho \imath \tau \rho \circ \pi \eta$ arguments were not logical proofs designed to establish the truth-value of those propositions or "some absolute truth about the world" (2010, p. 140). Rather, the charge of self-refutation was at least most of the time an intrinsically dialectical maneuver, for it was leveled in a dialectical context in which a claim was advanced, then attacked by an opponent (or even by oneself in foro interno), then defended against the attack, and so on. The purpose of the charge was to show that a given claim, even if true, could not be successfully advanced and defended in debate because of the unavoidable consequences to which, in such a dialectical exchange, its proponent was committed: by advancing and defending $p$ in debate, its proponent was either immediately or ultimately committing himself to not$p$, thereby being forced to admit defeat. One could then argue that there is a fifth type of self-refutation that should be labeled 'dialectical', ${ }^{15}$ and that DDA is a dialectical self-refutation argument. Whether or not we are willing to accept this further category of self-refutation argument is not important for present purposes. What is important is that, even though EWV or Pyrrhonism are not self-refuting in any of the four ways described above and even though DDA does not show that they are false, it is still a real problem for those stances if they are indeed self-undermining or self-defeating in the sense that they cannot be justifiably believed or legitimately asserted, given what they themselves claim, against someone who either challenges them or would challenge them if asked. So DDA seems to pose a serious epistemological challenge to both proponents of EWV and Pyrrhonian skeptics.

15 Cf. Burnyeat (1976, p. 59) and Castagnoli (2010, pp. 99-100). 


\section{Some conciliatory replies to DDA}

Until recently, conciliationists paid little attention to DDA, offering brief responses. In reply to Plantinga's original use of the argument against religious pluralism, Feldman (2003, pp. 89-90 with n. 4) maintains that the arguments against this view are unsuccessful, and so the exclusivist's reasons for rejecting it are not as good as the pluralist's reasons for endorsing it. If Feldman is right, then equal weight should not be given to the rival views about the correctness of the conciliatory principle defended by pluralists. Bogardus (2009, pp. 332-333) argues that EWV does not apply to the dispute between the conciliationist and the non-conciliationist because they are not epistemic peers, for the latter lacks the rational intuition that allows the former to just see the truth of EWV. In his first, succinct discussion of DDA, David Christensen (2009, pp. 762-763) acknowledges that his view is potentially self-undermining, since it undermines itself under certain evidential circumstances - in the present case, when he realizes that others reject the view. However, he thinks that conciliationists should not be seriously worried about this because it is not a problem restricted to their view, but common to any view on disagreement that is not radically steadfast.

Elga (2010) is the first to have offered a more detailed response to DDA. He claims that this argument is fatal against anyone who embraces across-the-board conciliationism, but that it does not represent a problem for partially conciliatory views, such as his own and those advocated by Christensen and Feldman. ${ }^{16}$ The reason is that, like any other fundamental policy, rule, or method, such views, in order to be consistent, must be dogmatic regarding their own correctness. Elga thinks that this move is not arbitrary because the restriction in question is precisely what makes his view partly conciliatory and because this kind of restriction is a common feature of many views about a wide range of topics.

Let me finally note that, in a more recent and fuller discussion of what he calls "Inconsistency Argument" (which is essentially similar to what I call DDA), Christensen offers a response partially similar to that provided in his 2009 article. He rightly points out that the argument can also be raised against moderately steadfast views (2013, p. 85). For these views recognize that peer disagreement does affect one's degree of credence in one's original position about the disputed issue, but claim that in at least many cases one need not compromise much because of the strength of the epistemic reasons undergirding one's original position. But insofar as there is some degree of compromise, one's moderately steadfast view will require one to become less confident in it. Moreover, not only any view of disagreement that is not completely steadfast but any view that allows for some degree of epistemic modesty will fall prey to DDA. Although Christensen still regards this as providing "a serious reason to be suspicious of the argument" (2013, p. 86), he proposes a different response to it based on what he calls "the conflicting-ideals view" (2013, pp. 92-93). According to this view, our rational ideals come into conflict in those circumstances in which there is good evidence against them, which however does not mean that any one of them is incorrect, but only that "one will end up violating some ideal or other,

16 On Christensen's and Feldman's views on disagreement, see Christensen (2007, 2009, 2010, 2011) and Feldman (2003, 2005, 2006, 2007, 2009). 
no matter what one ends up believing" (2013, p. 91). Although Christensen recognizes that the conflicting-ideals view is not "entirely comfortable" (2013, p. 92), he claims that the motivation for it is independent of the attempt to reply to DDA. For it is also motivated by those many cases in which one correctly assesses the first-order evidence (e.g., by realizing that $p$ is entailed by, or is the best explanation for, the first-order evidence), but then receives strong higher-order evidence against the correctness of such an assessment. In relation to DDA, the conflicting-ideals view explains how a conciliationist can cling to his position while acknowledging that doing so entails a violation of one of the rational ideals that lie behind that position, for violating such an ideal does not mean that the position is incorrect.

None of the above responses to DDA is the kind of answer a neo-Pyrrhonist would offer if confronted with this argument. Feldman's response would not do because both pluralist and exclusivist arguments strike the neo-Pyrrhonist as equipollent or equally credible. Unlike Bogardus, the neo-Pyrrhonist refrains from grounding his stance by an appeal to intuition, since there is great dispute over what intuition is and particularly whether it is a reliable means to justify our beliefs. One need only consider the current fierce debate about the reliability of intuition between analytic epistemologists and experimental philosophers. And more to the point of the present issue, the neoPyrrhonist would remark that defenders of steadfastness, too, may claim to have seen the truth of their view through intuition, in which case the debate between conciliationism and steadfastness would reach a deadlock. Unlike Christensen in his first response, the neo-Pyrrhonist does not believe that the severity of the problem is reduced by the mere fact that being potentially self-undermining is not a problem exclusive to conciliationism. If anything, this shows that it is a serious problem shared by several or many views. As for Elga's response, whereas his view is partially conciliatory, the neo-Pyrrhonist's suspension is global, since he withholds judgment on all the matters he has so far investigated. Also, as with Christensen's reply, Elga's appeal to the fact that a great many different kinds of views avoid the self-undermining objection by being dogmatic about their own correctness would not convince the neo-Pyrrhonist, who would instead ask whether that fact does not instead show that a large number of views make an arbitrary and questionable move. Finally, the neo-Pyrrhonist would not endorse Christensen's second response to DDA because it is based on a doxastic commitment to the canons of rationality. But he would regard that response as the most interesting of all in that it embodies a straightforward recognition of what strikes him as the aporetic aspect of rationality: by fully and conscientiously following the canons of rationality, one ends up in a situation of aporia in which those canons either undermine themselves or come into conflict with one another. In this regard, it is worth partially quoting the closing paragraphs of Christensen (2013):

the cases in which ideals conflict share an important feature: they all involve the results of agents reflecting critically on their own thinking. Perhaps it is not so surprising that insofar as it is rational to take seriously one's critical assessments of one's own beliefs, certain kinds of incoherence will result.

(...) The conflicting-ideals view simply allows us to recognize the rationality of acknowledging, and then taking serious account of, the possibility that we've fallen short of epistemic perfection. If we can accommodate that sort of modesty 
in our account of rational belief, it seems to me that it will be well worth the price of abandoning the hope that some cleanly specifiable notion of coherence is satisfied by the maximally rational response to every evidential situation. (p. 96)

Critical thinking that proceeds according to the standards of rationality may end up contravening one or another of those very standards when the epistemic modesty that is supported by the available evidence makes us doubt the correctness of even the most fundamental epistemic norms. One may therefore be incoherent even when being fully rational. I think that by at least some people's lights such a view would count as a form of skepticism about reason, even though it does not make Christensen himself lose his strong faith in reason.

\section{A neo-Pyrrhonian response}

So what kind of response to DDA could a neo-Pyrrhonist offer? Given the interpretation of Sextan Pyrrhonism proposed in Sect. 2, I think he could offer a three-stage response.

First, he would point out that his agnosticism is not a view he endorses as being epistemically justified, but a state of mind in which, as a matter of psychological fact, he finds himself after considering all the arguments advanced by the disagreeing parties. Thus, knowing about other people's rejection of suspension of judgment about the firstorder issues under dispute would not preclude the neo-Pyrrhonist from continuing to suspend judgment on those issues. That is, if the arguments pro and con the question whether $p$ continue to strike him as equally credible, he will as a matter of fact continue to refrain from making assertions about the question whether $p$. The neo-Pyrrhonian stance is therefore different from EWV, since proponents of this view put it forward as the correct answer to the question: what are we epistemically required to do in the face of peer dispute?

Second, when confronted with the second-order disagreement between those who affirm that first-order suspension or considerable belief revision is always epistemically required in the face of peer disagreement and those who deny this, the neo-Pyrrhonist would suspend judgment about this second-order debate between those two Dogmatic positions. For he asserts neither that suspension about first-order issues is the correct doxastic attitude that one should adopt when confronted with disputes between apparent epistemic peers, nor that there are principled and efficacious ways of settling at least some of those disputes. The arguments advanced by the proponents of conciliatory and steadfast views on peer disagreement strike him as epistemically equipollent. The neo-Pyrrhonist would also stress the fact that the Dogmatists themselves are unable to reach agreement about what rationality demands, epistemically speaking. This apparently intractable second-order dispute therefore favors the Pyrrhonian stance. Someone might object that, in suspending judgment about this second-order controversy, the neo-Pyrrhonist is in fact siding with the conciliationist. Once again, he would respond by saying that he withholds assent, not because he believes that it is epistemically required to give equal weight to the rival views every time there is a disagreement between apparent epistemic peers, but because he feels psychologically forced to 
suspend judgment when he cannot settle a dispute due to the apparent epistemic equipollence of the conflicting views.

Finally, if the proponent of DDA were not convinced by the preceding considerations, the neo-Pyrrhonist would make a final move by asking: what should one do if, as a matter of fact, one cannot decide whether (a) the affirmation that $p$, or (b) the denial that $p$, or (c) suspension of judgment about $p$ is the epistemically justified view to adopt regarding the question whether $p$ ? If the neo-Pyrrhonist applied the epistemic norm that the proponent of DDA himself endorses as correct, the neo-Pyrrhonist would come to the conclusion that second-order suspension is epistemically required. Epistemically speaking, one is required to suspend judgment if one is unable to decide whether (a), (b), or (c) is correct. The epistemic norm in question may be formulated thus:

It is epistemically required to suspend judgment in the face of a disagreement that one is unable to resolve due to the epistemic symmetry of the conflicting views.

If the neo-Pyrrhonist adopted this epistemic norm, he would be required to suspend judgment because the parties to the disagreements he has so far considered strike him as equally justified. If the proponent of DDA were to argue that the situation of symmetry and unresolvability does not obtain in the debate between conciliationists and non-conciliationists and hence that suspension is not epistemically required in this case, the neo-Pyrrhonist would kindly ask him to share the arguments that compellingly and impartially establish that only one of the contending parties is epistemically justified. ${ }^{17}$ From the vantage point of the neo-Pyrrhonist, conciliationists and non-conciliationists disagree and they seem to have disclosed all the available relevant evidence and arguments, and to be well aware of the pertinent conceptual distinctions and analyses. Conciliationists like David Christensen, Adam Elga, and Richard Feldman, on the one hand, and non-conciliationists like Thomas Kelly, Ernest Sosa, and Peter van Inwagen, ${ }^{18}$ on the other, engage in an elaborate dialectical exchange and neither side succeeds in persuading the other. They are all intellectually respected and well-trained philosophers who do not come to an agreement and it is not clear how such a dispute could be impartially settled. If we compare any pair of philosophers, taking one from each camp, we might identify relevant epistemic differences, but this seems much less feasible if the comparison is between the two camps as a whole. To make matters worse, the proponents of each view advocate different variants of both conciliationism and steadfastness. As an external onlooker on the debate about the epistemic significance of peer disagreement who has taken no stand on the matter and is looking for answers, the neo-Pyrrhonist witnesses two groups of seemingly intelligent, informed, well-trained, and careful philosophers who fail to agree about what

17 In reply to a referee's comment, I should note that what I say here in no way implies that the proponent of DDA is committed to EWV. I do not claim that the proponent of DDA is epistemically required to suspend judgment in the face of the second-order dispute about the epistemic significance of disagreement, for he denies that the situation of epistemic symmetry obtains in most disagreements, including the one between conciliationists and non-conciliationists.

18 For the steadfast views of these authors, see Kelly (2005, 2010), Sosa (2010), and Inwagen (1996); van Inwagen (2010). 
the arguments establish. Granting that the arguments of one of the groups are sound, this means that the members of the other group, despite their information, training, and intellectual virtues, are unable to see the soundness of those arguments. The problem for the neo-Pyrrhonist is that the members of each camp claim that it is the members of the other camp who, notwithstanding being their apparent epistemic peers, are unable to properly assess the soundness of the arguments. Hence, if pressed with the selfdefeat charge, the neo-Pyrrhonist would shrug his shoulders with resignation and ask how he is supposed to adjudicate the debate in a way that could be considered neutral, unbiased, and compelling by all the parties to the debate. He is therefore in a situation of aporia, given that he is confronted with competing views that strike him as equally justified and he lacks a clear-cut and agreed-upon criterion that would make it possible to choose between those views. Moreover, he would point out that, if he applied the epistemic norms endorsed by the Dogmatists, he would find himself in a situation similar to that described by Christensen's conflicting-ideals view. Indeed, in the face of pervasive disagreements between positions that strike one as equally justified, one is epistemically required to suspend judgment across the board, but in so doing one falls prey to the dialectical self-defeat charge, which means that global agnosticism cannot be justifiably believed or asserted in the event that someone calls into question its correctness or would call it into question if asked. As noted at the end of the previous section, this illustrates what strikes the neo-Pyrrhonist as the aporetic aspect of rationality.

\section{Objections and replies}

I would now like to consider five objections that could be raised to the neo-Pyrrhonian response to DDA and explain why they miss the mark.

First, it could be argued that, in the third move of that response, the topic has switched back to epistemic norms, instead of just psychological reports on the neoPyrrhonist's personal experience. The neo-Pyrrhonist's recommendation is, in the face of the second-order disagreement between conciliationists and non-conciliationists, to suspend judgment. But that is just what the conciliatory view recommends, and what got this view into the problem of self-defeat in the first place: in the face of disagreement about the conciliatory view itself, this view says that we should not believe it. This objection misunderstands the ad hominem nature of the third move made by the neo-Pyrrhonist, since in this move he is not relying on an epistemic norm that he himself endorses as correct, but on an epistemic norm endorsed as correct by the proponent of DDA. The neo-Pyrrhonist asks the proponent of DDA: given the epistemic norm that you yourself endorse as correct, how should one react when one is unable to resolve both first- and second-order disagreements between apparent epistemic peers owing to the seeming epistemic equipollence of the views defended by the disagreeing parties?

Secondly, it could be objected that the neo-Pyrrhonian response is not relevant to the contemporary debate: by making no assertion about what is epistemically required, the neo-Pyrrhonist seems to have changed the subject. The subject was: what should we say about certain views that seem to recommend against themselves in certain situations? But neo-Pyrrhonism makes no recommendations, and so cannot recommend against 
itself. So why think that the neo-Pyrrhonian response to DDA is relevant to the subject at hand? In reply, I must remind the reader that my aim in examining the kind of response a neo-Pyrrhonist could offer to DDA is not to defend EWV or conciliationism more generally, but to better understand his peculiar kind of skepticism. DDA seems to be a compelling argument against conciliationism precisely because conciliationists, unlike neo-Pyrrhonists, recommend what they regard as an epistemically justified view on peer disagreement. So, in responding to DDA the way he does, the neo-Pyrrhonist has indeed changed the subject, but only in the sense that he shows that, despite first appearances, the self-defeat charge can be leveled against his stance only if one misunderstands the sui generis character of his skepticism.

Thirdly, and relatedly, it could be observed that, while EWV is a normative thesis and DDA poses a normative problem, the neo-Pyrrhonian response to DDA makes a factual point, and so it is not clear how this response bears on the normative problem. In reply, I must once again remind the reader that my aim has been to show that, even though one might be inclined to think that DDA could also be legitimately leveled against Pyrrhonism, this would be possible only if one misunderstood the nature of this form of skepticism by claiming that the Pyrrhonian skeptic is normatively committed to regarding suspension of judgment as rationally appropriate instead of being psychologically constrained to suspend judgment. The normative problem posed by DDA does not arise for the neo-Pyrrhonist because his suspension of judgment is not a based on an epistemic norm. If, as a referee has noted, the proponent of DDA need not deny that advocates of a view can persist in holding it nonetheless through stubbornness or through being psychologically forced in some other way, then he would concede that Pyrrhonian skepticism as it has been interpreted in this paper is not vulnerable to the charge of dialectical self-defeat.

Fourthly, it could be objected that, if the neo-Pyrrhonist does not take suspension of judgment to be the doxastic attitude that one is epistemically required to adopt in the face of equipollent disagreement, then neo-Pyrrhonism is deprived of any philosophical interest, particularly to epistemologists. For when we read Sextus's writings, we are just reading the auto-biographical report of personal experiences that contains no normative claims. Even though I think it is undeniable that many will dismiss out of hand the Pyrrhonian stance as it has been portrayed here, nothing necessarily prevents people from finding Sextus's texts philosophically challenging and intriguing. For example, someone may believe that the epistemological arguments that Sextus expounds but from which he withholds assent are sound and that they show that it is impossible to justify our beliefs or to settle disagreements. We should keep in mind that whether someone is convinced or persuaded by a given argument does not necessarily depend upon whether the person who presents the argument is committed to its soundness. ${ }^{19}$ Also, someone may, despite deeming Pyrrhonism unpersuasive or far-fetched,

\footnotetext{
19 A reviewer has suggested that at this point my response to the fourth objection is similar to the response that Ribeiro (2011, p. 23) offers to an argument analogous to DDA that could be leveled against his disagreement-based skepticism about the rationality of philosophical discourse. There is, however, at least one crucial difference: whereas Ribeiro believes that his disagreement-based skeptical argument is sound, Sextus is not committed to the soundness of the arguments he advances, which is precisely what motivates the fourth objection.
} 
find it philosophically stimulating in that it makes him consider more carefully or in a new light problems concerning disagreement, justification, and rationality. Something of this sort is what explains the interest in Pyrrhonism among contemporary epistemologists. Let me finally note that whether the neo-Pyrrhonist is doing epistemology depends on how one conceives of this activity. ${ }^{20}$ If for someone to do epistemology it is required that he endorse some theory about the nature and the possibility of knowledge and justification, then it is plain that the neo-Pyrrhonist is not doing epistemology. But if for someone to do epistemology it is only required that he be able to examine and discuss the claims and arguments of those who hold any such theory, then there is no reason for denying that he is doing epistemology. The fact that the neo-Pyrrhonist has no epistemological commitments should not make us lose sight of the fact that he does not deny the possibility of the epistemological project, but only suspends judgment about it. Indeed, given that he open-mindedly keeps on investigating whether there is a truth about the matters on which he has so far suspended judgment, he sincerely and carefully assesses the epistemic credentials of the views he examines. ${ }^{21}$

Fifthly, it could be argued that, given that his stance is not an epistemological view, the neo-Pyrrhonist would not feel compelled to reply to DDA. Offering a reply would imply, or be a recognition, that he endorses an epistemological view. My response is twofold. First, in case someone thought that DDA may be properly advanced against Pyrrhonian skepticism, a neo-Pyrrhonist might want to make it clear why such an argument misses the mark when directed against his skeptical outlook. Sextus in fact constantly tries to dispel misunderstandings about the nature and scope of Pyrrhonism. For instance, he takes great pains to distinguish Pyrrhonism from various positions with which it could be mistaken in order that one may understand more clearly the Pyrrhonian perspective ( $P H$ I 210-241). One may suppose that he would likewise want to distinguish Pyrrhonism from EWV (or conciliationism in general) in case the two outlooks were taken to be remarkably similar. Second, even if no neo-Pyrrhonist would bother to respond to DDA on the grounds that he is not putting forth an epistemological view, interpreters of Pyrrhonian skepticism might find it enlightening to examine the kind of reply a neo-Pyrrhonist could offer to such an argument, as I have tried to do in the present paper.

\section{Conclusion}

DDA does not purport to show that EWV or Pyrrhonism are false. Rather, it purports to show that in a given dialectical context—when someone disagrees about their correctness or would disagree about it if asked - they are self-defeating in the sense that they should be applied to themselves with the result that they cannot be justifiably believed or legitimately asserted. I have argued that, even though DDA might be efficacious against EWV or conciliationism more generally, the neo-Pyrrhonist's stance is not dialectically self-defeating because he conceives of his suspension of judgment in the

\footnotetext{
20 In the rest of this paragraph, I draw on Machuca (2015, p. 34).

21 In Machuca (2013a), I examine several issues in the epistemology of disagreement from a neo-Pyrrhonian perspective.
} 
face of equipollent disagreement as a psychological disposition forced upon him and not as a doxastic attitude he is epistemically required to adopt.

Acknowledgements This paper began life as part of a talk I gave at Northwestern University in September 2011. An abridged version was presented at the Center for Hellenic Studies in April 2012. A fuller version was given at a conference on ancient and contemporary Pyrrhonism held at the Universidade Federal do Paraná in May 2013. I am grateful to the participants at that conference-in particular, Richard Bett and Stéphane Marchand-for their critical remarks. I would also like to thank three referees for Synthese for their comments and questions, which allowed me to clarify the aim of this paper and the nature of the neo-Pyrrhonian response to DDA.

\section{References}

Barnes, J. (1990). Pyrrhonism, belief and causation: Observations on the scepticism of Sextus Empiricus. In W. Haase (Ed.), Aufstieg und Niedergang der römischen Welt II 36.4 (pp. 2600-2695). Berlin: de Gruyter.

Bergmann, M. (2009). Rational disagreement after full disclosure. Episteme, 6, 336-353.

Bogardus, T. (2009). A vindication of the equal-weight view. Episteme, 6, 324-335.

Burnyeat, M. (1976). Protagoras and self-refutation in later Greek philosophy. The Philosophical Review, $85,44-69$.

Castagnoli, L. (2010). Ancient self-refutation: The logic and history of the self-refutation argument from Democritus to Augustine. Cambridge: Cambridge University Press.

Christensen, D. (2007). Epistemology of disagreement: The good news. The Philosophical Review, 116, $187-217$.

Christensen, D. (2009). Disagreement as evidence: The epistemology of controversy. Philosophy Compass, 4, 756-767.

Christensen, D. (2010). Higher-order evidence. Philosophy and Phenomenological Research, 81, 185-215.

Christensen, D. (2011). Disagreement, question-begging and epistemic self-criticism. Philosophers' Imprint, 11(6), 1-22.

Christensen, D. (2013). Epistemic modesty defended. In D. Christensen \& J. Lackey (Eds.), The epistemology of disagreement: New essays (pp. 77-97). Oxford: Oxford University Press.

Elga, A. (2010). How to disagree about how to disagree. In R. Feldman \& T. Warfield (Eds.), Disagreement. New York: Oxford University Press.

Enoch, D. (2010). Not just a truthomether: Taking oneself seriously (but not too seriously) in cases of peer disagreement. Mind, 119, 953-997.

Feldman, R. (2003). Plantinga on exclusivism. Faith and Philosophy, 20, 85-90.

Feldman, R. (2005). Respecting the evidence. Philosophical Perspectives, 19, 95-119.

Feldman, R. (2006). Epistemological puzzles about disagreement. In S. Hetherington (Ed.), Epistemology futures (pp. 216-236). New York: Oxford University Press.

Feldman, R. (2007). Reasonable religious disagreements. In L. Antony (Ed.), Philosophers without gods: Meditations on atheism and the secular life (pp. 194-214). Oxford: Oxford University Press.

Feldman, R. (2009). Evidentialism, higher-order evidence, and disagreement. Episteme, 6, 294-312.

Kelly, T. (2005). The epistemic significance of disagreement. Oxford Studies in Epistemology, 1, 167-196.

Kelly, T. (2010). Peer disagreement and higher-order evidence. In R. Feldman \& T. Warfield (Eds.), Disagreement (pp. 111-174). New York: Oxford University Press.

Lammenranta, M. (2008). The Pyrrhonian problematic. In J. Greco (Ed.), The Oxford handbook of skepticism (pp. 9-33). New York: Oxford University Press.

Lammenranta, M. (2011). Skepticism and disagreement. In D. E. Machuca (Ed.), Pyrrhonism in ancient, modern, and contemporary philosophy. Dordrecht: Springer.

Machuca, D. E. (2009). Argumentative persuasiveness in ancient Pyrrhonism. Méthexis, 22, 101-126.

Machuca, D. E. (2011). Pyrrhonism and the law of non-contradiction. In D. E. Machuca (Ed.), Pyrrhonism in ancient, modern, and contemporary philosophy (pp. 51-77). Dordrecht: Springer.

Machuca, D. E. (2013a). A neo-Pyrrhonian approach to the epistemology of disagreement. In D. E. Machuca (Ed.), Disagreement and Skepticism (pp. 66-89). New York: Routledge.

Machuca, D. E. (2013b). Pyrrhonism, inquiry, and rationality. Elenchos, 34, 201-228. 
Machuca, D. E. (2013c). Pyrrhonism. In D. Pritchard (Ed.), Oxford bibliographies in philosophy. New York: Oxford University Press. doi:10.1093/OBO/9780195396577-0240.

Machuca, D. E. (2015). Agrippan Pyrrhonism and the challenge of disagreement. Journal of Philosophical Research, 40, 23-39.

Machuca, D. E. (forthcoming). Scepticisme, apraxia et rationalité. In D. Machuca \& S. Marchand (Eds.), Pour et contre: études sur le scepticisme antique. Paris: Classiques Garnier.

Mackie, J. L. (1964). Self-refutation: A formal analysis. The Philosophical Quarterly, 14, 193-203.

McPherran, M. (1987). Skeptical homeopathy and self-refutation. Phronesis, 32, 290-328.

Pentzopoulou-Valalas, T. (1994). Le rationalisme des sceptiques grecs. In J. Lagrée \& D. Delattre (Eds.), Ainsi parlaient les anciens (pp. 239-251). Paris: Presses Universitaires de Lille.

Perin, C. (2006). Pyrrhonian scepticism and the search for truth. Oxford Studies in Ancient Philosophy, 30, 337-360.

Perin, C. (2010). The demands of reason: An essay on Pyrrhonian scepticism. Oxford: Oxford University Press.

Plantinga, A. (2000a). Pluralism: A defense of religious exclusivism. In K. Meeker \& P. Quinn (Eds.), The philosophical challenge of religious diversity (pp. 172-192). New York: Oxford University Press.

Plantinga, A. (2000b). Warranted christian belief. Oxford: Oxford University Press.

Ribeiro, B. (2011). Philosophy and disagreement. Crítica, 43, 3-25.

Sosa, E. (2010). The epistemology of disagreement. In A. Haddock, A. Millar, \& D. Pritchard (Eds.), Social epistemology (pp. 278-297). Oxford: Oxford University Press.

Thune, M. (2010a). 'Partial defeaters' and the epistemology of disagreement. The Philosophical Quarterly, $60,355-372$.

Thune, M. (2010b). Religious belief and the epistemology of disagreement. Philosophy Compass, 5, 712724.

Turri, J. (2012). A puzzle about withholding. The Philosophical Quarterly, 62, 355-364.

van Inwagen, P. (1996). It is wrong, everywhere, always, and for anyone, to believe anything upon insufficient evidence. In J. Jordan \& D. Howard-Snyder (Eds.), Faith, freedom, and rationality (pp. 137-153). London: Rowman \& Littlefield.

van Inwagen, P. (2010). We're right. They're wrong. In R. Feldman \& T. Warfield (Eds.), Disagreement (pp. 10-28). New York: Oxford University Press.

Weatherson, B. (2013). Disagreements, philosophical, and otherwise. In D. Christensen \& J. Lackey (Eds.), The epistemology of disagreement: New essays (pp. 54-73). Oxford: Oxford University Press. 